\title{
Biological Characteristics of the Spotcheek Emperor, Letbrinus rubrioperculatus, in the Northern Mariana Islands ${ }^{1}$
}

\author{
Michael S. Trianni ${ }^{2}$
}

\begin{abstract}
As a result of commencement of an incipient commercial fishery in the southern islands (SI) of the Commonwealth of the Northern Mariana Islands (CNMI), biological characteristics for the spotcheek emperor, Lethrinus rubrioperculatus, were estimated from the CNMI SI, including seasonality of spawning, sex ratios, length at sexual maturity $\left(\mathrm{L}_{\mathrm{M}}\right)$, length at transition $\left(\mathrm{L}_{\mathrm{T}}\right)$ to male phase, age, and growth. $\mathrm{L}_{\mathrm{M}}$ and $\mathrm{L}_{\mathrm{T}}$ estimates corresponded to ages of 1 and 3-4 $\mathrm{yr}$, respectively, and are important in managing hermaphroditic species such as the spotcheek emperor by ensuring that fishery size selection does not significantly reduce effective stock reproduction. Age of the oldest fish was $8 \mathrm{yr}$, with South Southern Islands (SSI) fish mostly 0-2 yr old and North Southern Islands (NSI) fish 1-4 yr old. Average size of 0 -age fish was $22.2 \mathrm{~cm}$ fork length $\left(\mathrm{L}_{\mathrm{F}}\right)$ from the SSI and $18.7 \mathrm{~cm} \mathrm{LF}$ from the NSI, indicating an initial high growth rate not captured by specimen collection. Growth curves for the NSI and SSI were significantly different at the $5 \%$ level. Age and growth parameters were estimated using age- and length-based methods, which resulted in similar values for instantaneous growth coefficient $(\mathrm{k})$ and asymptotic length $\left(\mathrm{L}_{\infty}\right)$. Results support further study into life history characteristics of the spotcheek emperor, in particular maximum age and lengths at maturity and transition, in other locations in the CNMI SI as well as in other Indo-Pacific jurisdictions.
\end{abstract}

In the Commonwealth of the Northern Mariana Islands (CNMI), the spotcheek emperor, Letbrinus rubrioperculatus (Sato, 1978), serves as an important component of a wide range of cultural gatherings such as weddings, fiestas, and funeral rosaries. Estimates of biological parameters pertinent to evaluation of stock status for the spotcheek emperor in the CNMI became a management goal emanating from expanding fishing effort by the largevessel $(>18 \mathrm{~m})$ bottom fishery during the mid-

\footnotetext{
${ }^{1}$ Support for this research project came from the U.S. Fish and Wildlife Service Dingell-Johnson Sportfish Restoration Act. Manuscript accepted 8 September 2010.

${ }^{2}$ Commonwealth of the Northern Mariana Islands, Division of Fish and Wildlife, Department of Lands and Natural Resources, P.O. Box 10007, Saipan, MP 96950 (phone: 1-670-664-6041; fax: 1-670-664-6056; e-mail: mstdfw@yahoo.com).
}

Pacific Science (2011), vol. 65, no. 3:345-363

doi: $10.2984 / 65.3 .345$

(C) 2011 by University of Hawai'i Press

All rights reserved to late 1990s. This resulted in a research program conducted by the CNMI Division of Fish and Wildlife (DFW) that collected data through a port-sampling program and research surveys from 1996 to 2002 . In addition, the 1996 Magnuson-Stevens Fishery Management and Conservation Act (MSFMCA) required Fishery Councils to end overfishing and rebuild overfished stocks through a precautionary management approach (Restrepo and Powers 1999). Subsequently, the 2006 reauthorization of the MSFMCA stipulated that annual catch limits and accountability measures be derived for primary target species under all Fishery Council jurisdictions, and the spotcheek emperor in the CNMI falls into that category because it is a primary management unit species under the Mariana Islands Fishery Ecosystem Plan as authorized by the Western Pacific Regional Fishery Management Council (WPRFMC). The goals of the CNMI DFW research program were to obtain data pertaining to life history characteristics of this species for stock assessment purposes. 
Although a dominant species landed in coral reef fisheries of the Indo-Pacific Region within the 50 to $80 \mathrm{~m}$ depth range (Carpenter and Allen 1989, Dalzell et al. 1996), the spotcheek emperor has been the focus of few studies. Nzioka (1979) and Loubens (1980) reported biological data from Southern Hemisphere studies of Lethrinus variegatus, regarded by Ebisawa (1997) as misidentifications of L. rubrioperculatus; Ralston and Williams (1988) conducted age and growth analysis in American Samoa; Hanoomanjee and Soondron (1999) obtained biological parameters from Mauritius in the West Indian Ocean; and from the Ryukyu Islands of the Okinawa Prefecture of southern Japan, Ebisawa (1997) conducted reproductive studies establishing sequential protogeny, and Ebisawa and Ozawa (2009) provided age and growth estimates.

Biological characteristics of the spotcheek emperor are summarized in this article for $L$. rubrioperculatus in the southern islands of the CNMI.

\section{MATERIALS AND METHODS}

\section{Study Site}

The primary fishing grounds for the spotcheek emperor in the CNMI comprise the islands and banks of the Mariana archipelago referred to as the "Southern Island Arc" (SI) from Rota Island $\left(14^{\circ} 09^{\prime} 13^{\prime \prime} \mathrm{N}, 145^{\circ} 12^{\prime} 11^{\prime \prime} \mathrm{E}\right)$ to Sonome Reef $\left(16^{\circ} 20^{\prime} 60^{\prime \prime} \mathrm{N}, 145^{\circ} 40^{\prime} 00^{\prime \prime} \mathrm{E}\right)$ north of Farallon de Medinilla (FDM), with fishing effort focused from Tatsumi Reef south of Tinian to Sonome Reef (Figure 1). Fishing grounds can be further broken down into two distinct subregions: the South Southern Islands (SSI), from Tatsumi Reef north to Marpi Reef, and the North Southern Islands (NSI), from FDM north to Sonome Reef. These subregions correspond to different fishing effort regimes, in which effort in the SSI has been primarily from small artisanal boats $(<12 \mathrm{~m})$ proximal to the large population centers of the CNMI, and the NSI fishing effort has been primarily from a temporally variable large commercial vessel $(>15 \mathrm{~m})$ fleet. In addition, the two subregions differ with respect to spotcheek emperor fishing grounds. The SSI include islands with limited contiguous habitat as well as submerged banks, and the NSI are primarily submerged banks, including the largest bank in the Marianas, around the island of FDM. In this study the SSI included Tinian (Tatsumi Reef included), Saipan, and Marpi Reef. The NSI included FDM and Sonome Reef, with White Tuna and ESE Reef included with Sonome Reef. Commercially port-sampled data were all from the NSI, and research sampled data were from the NSI (FDM) and SSI.

\section{Data Collection}

Length frequency and biological data were collected during port sampling of CNMI NSI commercial landings from 1996 to 2001, and from DFW research surveys from 1998 to 2002. Commercial fishing vessels were sampled upon return from NSI fishing grounds, with fish randomly sampled as vessels offloaded their catch. Commercial fishing activity in the NSI was temporally variable due to oceanographic conditions as well as vessel maintenance, and only one vessel arrived at port at any one time. DFW research surveys were conducted diurnally using two fiberglass poles and 12-volt powered hosting Penn Senator reels (Electramate), with a lead-weighted monofilament line with four circle hooks baited with cut squid as the terminal rig, accomplished by performing a series of uninterrupted drifts over a depth range from 50 to $100 \mathrm{~m}$, including the primary fishing grounds and habitat of the spotcheek emperor.

Identical data-collection protocols were used for both DFW surveys and commercial sampled fish. Length frequency data were collected from sampled fish to the nearest $\mathrm{mm}$ fork length $\left(\mathrm{L}_{\mathrm{F}}\right)$, with subsamples weighed to the nearest $0.1 \mathrm{~g}$. Beginning in 1998, $30 \mathrm{spec}-$ imens were targeted each month for reproductive data collection. Gonads were excised for macroscopic sex identification and weighed to the nearest $0.01 \mathrm{~g}$ using an electronic scale. Gonado-Somatic Index values were calculated as the percentage weight of gonad $(\mathrm{g})$ over fish weight (g). Specimens were assigned to either an immature or a sexually active class 
a.

Stingray Shoals

Bank C

Bank D o

Pathfinder Reef "

Arakane Reef \

Bank A o
- Uracas

- Maug Islands

- Ascunsion
ePagan

* Alamagan

* Guguan

\section{Sarigan :}

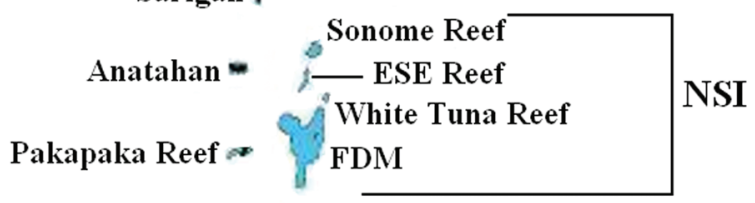

Marpi Reef

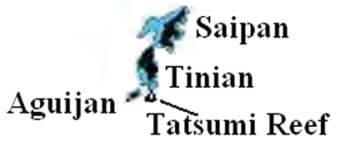

Guam

Rota

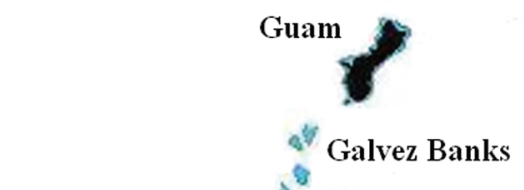

Santa Rosa Reefs

Figure 1. The Mariana archipelago highlighting the Southern Island Arc. Islands are shown in black and extent of $100 \mathrm{~m}$ contour in lighter shading.

based upon external examination (Table 1). lowing water cleansing and drying, otoliths Sagittal otoliths were collected from a sub- were weighed to the nearest $0.0001 \mathrm{~g}(0.1 \mathrm{mg})$ sample of the specimens processed for reproductive data, beginning in August 2000. Folusing an electronic balance, to evaluate the relationship between otolith weight and fish 
TABLE 1

Criteria Used for Determination of Maturity Class for Letbrinus rubrioperculatus from the Northern Mariana Islands

\begin{tabular}{|c|c|c|}
\hline Stage & External Appearance & Maturity Class \\
\hline Immature & Gonads small, slender, pinkish in color. Individual eggs not discernable. & Immature \\
\hline Developing/Maturing & $\begin{array}{l}\text { Ovaries elongated, swollen in girth. Individual ova discernable through } \\
\text { ovarian membrane. Color pinkish to yellowish. }\end{array}$ & Sexually active \\
\hline Ripe & $\begin{array}{l}\text { Ovaries elongated and very swollen with large ripe ova visible through } \\
\text { ovarian membrane. Ova easily exuded upon application of pressure. } \\
\text { Ovary wall thin. Color yellowish. }\end{array}$ & Sexually active \\
\hline Spent & $\begin{array}{l}\text { Ovaries flaccid, partially empty in appearance, with color faded from } \\
\text { dark yellow to brown. Ovary wall thick. }\end{array}$ & Sexually active \\
\hline
\end{tabular}

$\mathrm{L}_{\mathrm{F}}$ for potential future use as a proxy for age. Sagittal otoliths were processed to produce transverse sections for determining the age of individual fish following the method described in Choat and Axe (1996). The median value of three blind reads for each specimen was used for age assignment. Otolith ages were assigned based upon the number of opaque rings or "annual increments" emanating from the core to the outer otolith edge. Due to their protracted spawning seasons, many tropical fish do not possess a fixed "birth date" per se as temperate species do. As a result, the first annual increments may be laid down when a fish is only a few months old. Therefore, the first annual increment was not counted if located too close to the otolith core, resulting in some 0 -age fish being older than $1 \mathrm{yr}$. Otoliths identified as 0 age or otoliths for which one read resulted in a 0 -age assignment were evaluated by counting daily rings following methods outlined in Secor et al. (1991). Otolith processing and reading was conducted by the Fish Ageing Laboratory at James Cook University, Townsville, Australia.

\section{Reproduction}

Sex ratios were determined for Tinian, Saipan, and Marpi Reef in the SSI, and FDM and Sonome Reef in the NSI. Sex ratios for the NSI and SSI were examined using Pearson's $\chi^{2}$ goodness-of-fit test with Yate's continuity correction factor. Following assignment to either an immature or a sexually active maturity class, fish were assigned to a $1 \mathrm{~cm} \mathrm{~L} \mathrm{~L}_{\mathrm{F}}$ class for length at maturity $\left(\mathrm{L}_{M}\right)$ analysis. The number of identified females and males was used to estimate the length at transition $\left(\mathrm{L}_{\mathrm{T}}\right)$. The logistic model was used to correlate percentage mature and percentage transitioned, to length class:

$$
P=1 /\left(1+e^{-\left(a+b L_{j}\right)}\right),
$$

where $P=$ percentage mature or transitioned in size class, $a$ and $b$ are model parameters, and $\mathrm{L}_{50}=-a / b$. The model was weighted by the square root of the numbers of fish in each length class, and the regression parameters were estimated using maximum likelihood with a binomial logistic link function. Separate estimates of $\mathrm{L}_{M}$ and $\mathrm{L}_{T}$ were generated for the SSI and NSI. Bias corrected percentile confidence intervals were produced around the estimates of $\mathrm{L}_{M}$ and $\mathrm{L}_{\mathrm{T}}$ from 1,000 bootstrap re-samples drawn with replacement for each estimate of $\mathrm{L}_{M}$ and $\mathrm{L}_{\mathrm{T}}$. Data analyses were conducted using S-PLUS version 6.2 (Insightful Corp. 2003).

\section{Age and Growth}

The von Bertalanffy growth function (von Bertalanffy 1938) was fit to size at age data for all samples, separate male and female samples, and separately for SSI and NSI samples, using the simplex solver in Excel. The von Bertalanffy (VB) growth function is defined as:

$$
L_{t}=L_{\infty}\left(1-e^{-k\left(t-t_{0}\right)}\right) \text {, }
$$

where $L_{t}=$ length at time $t, L_{\infty}=$ asymptotic length, $k=$ instantaneous growth coefficient, 
and $t_{0}=$ theoretical time at which length is equal to 0 .

The growth curves generated from the VB fitting procedure were subsequently tested for equality using the analysis of residual sum of squares method (ARSS) developed by Chen et al. (1992). In addition to age-based estimates, length-based VB parameters were estimated using the ELEFAN model (Gayanilo and Pauly 1997). DFW research cruise $L_{F}$ data were combined with commercial $\mathrm{L}_{\mathrm{F}}$ data in the analysis, and data were grouped into quarters of a year because monthly data were not always available due to fishing inactivity caused by oceanographic conditions or vessel maintenance. Parameters of the length-weight relationship were obtained by fitting the power function $W=a \times \mathrm{L}_{\mathrm{F}}^{b}$ to length and weight data, where $W$ is the total wet weight, $a$ is a constant, and $b$ is the associated growth parameter.

\section{RESULTS}

\section{Reproduction}

The sex ratios from commercial and research survey data are presented in Table 2. FDM was the only location where both CNMI commercial and DFW research data were collected, and the sex ratios differed, with commercially caught fish exhibiting a male bias and research-caught fish a female bias similar to the Marpi Reef sex ratio. Overall, there were clear differences in the sex ratios from the NSI and SSI, most notably between the NSI and Saipan and Tinian. A Pearson $\chi^{2}$ test found that the overall sex ratios from the
NSI and SSI were significantly different from expected $\left(\chi^{2}=26.38, \mathrm{df}=1, P>.0001\right)$. A Pearson $\chi^{2}$ test for commercial and DFW survey-generated sex ratios from FDM was not significant $\left(\chi^{2}=0.98, \mathrm{df}=1, P=.322\right)$. A difference was observed between sex ratios of Marpi Reef and those of Saipan and Tinian, with Marpi Reef exhibiting a sex ratio similar to that in the NSI.

Histograms of the frequency of occurrence by sex of the spotcheek emperor from the NSI and SSI are shown in Figure 2. The female and male size distributions overlap, with males generally larger than females. The length characteristics for males and females from NSI (Sonome Reef and FDM) and SSI (Saipan/Tinian and Marpi Reef) showed that the smallest female and smallest male were documented from Saipan/Tinian, at $14.7 \mathrm{~cm}$ $\mathrm{L}_{\mathrm{F}}$ and $19.3 \mathrm{~cm} \mathrm{~L} \mathrm{~L}_{\mathrm{F}}$, respectively; the largest male was recorded from Sonome Reef, at 45.6 $\mathrm{cm} \mathrm{LF}$; the largest female, at $37.7 \mathrm{~cm} \mathrm{LF}$, from Saipan/Tinian; and the smallest mature female, at $18.4 \mathrm{~cm} \mathrm{LF}$, from Sonome Reef.

Spawning data were aggregated monthly over the period from February 1998 through November 2001 (Figure 3). The availability of monthly samples varied according to commercial fishing effort or weather conditions. The spawning period for females began in January and extended to September with peak activity from January to March. The peak spawning period for males was less defined, appearing to extend from December to August with reduced spawning activity in January.

TABLE 2

Sex Ratios of L. rubrioperculatus from the CNMI

\begin{tabular}{lcccc}
\hline \hline Location & Female & Male & $n$ & Source \\
\hline NSI & & & & \\
$\quad$ Sonome Reef & 52 & 48 & 699 & CNMI DFW \\
FDM & 51 & 49 & 323 & CNMI DFW \\
$\quad$ Commercial & 46 & 46 & 284 & CNMI DFW \\
$\quad$ DFW Survey & 54 & 44 & 205 & CNMI DFW \\
SSI & 56 & 17 & 167 & CNMI DFW \\
Marpi Reef & 83 & 11 & 128 & \\
Saipan & 89 & & & \\
Tinian & & & \\
\hline
\end{tabular}




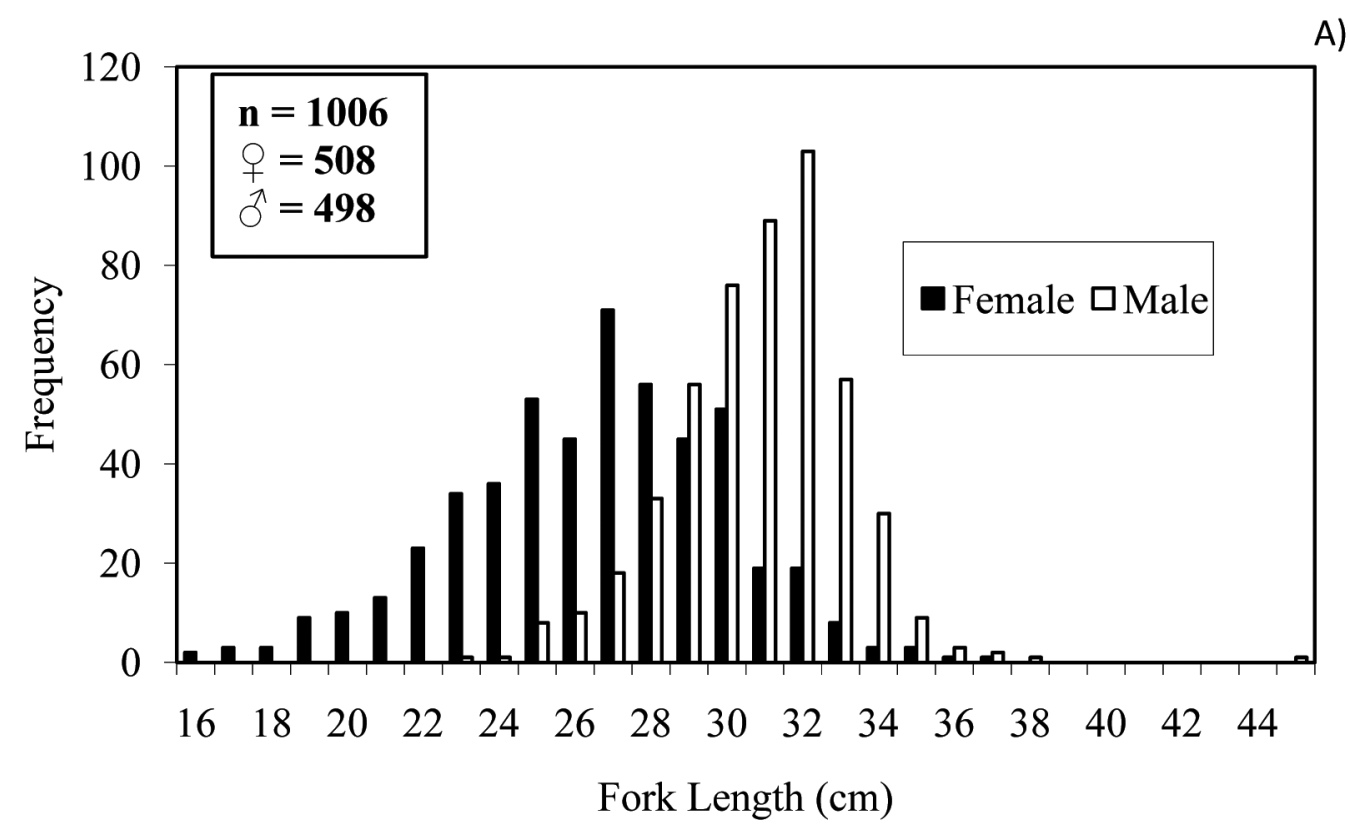

B)

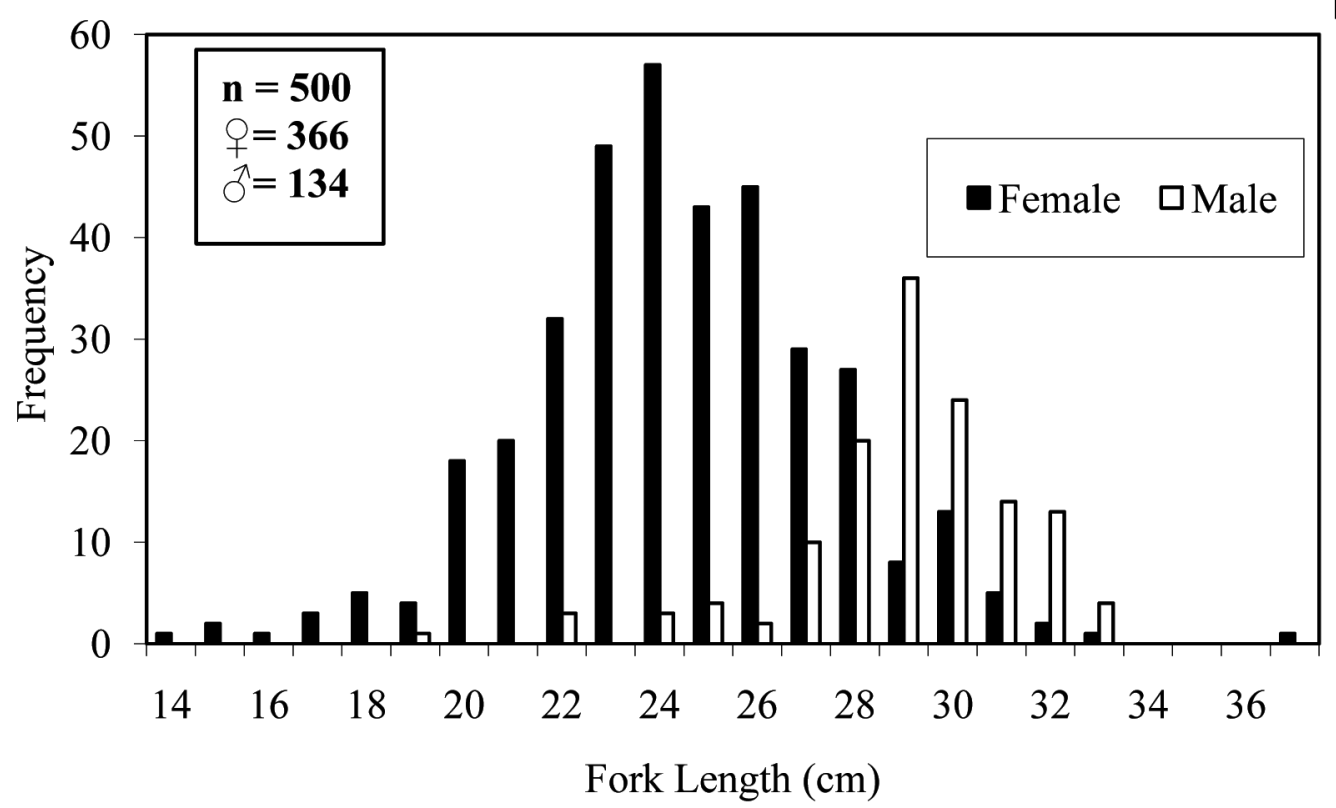

FIGURE 2. Histograms of the frequency of occurrence by sex of the spotcheek emperor in the southern islands of the CNMI from the NSI $(A)$ and SSI $(B)$. 

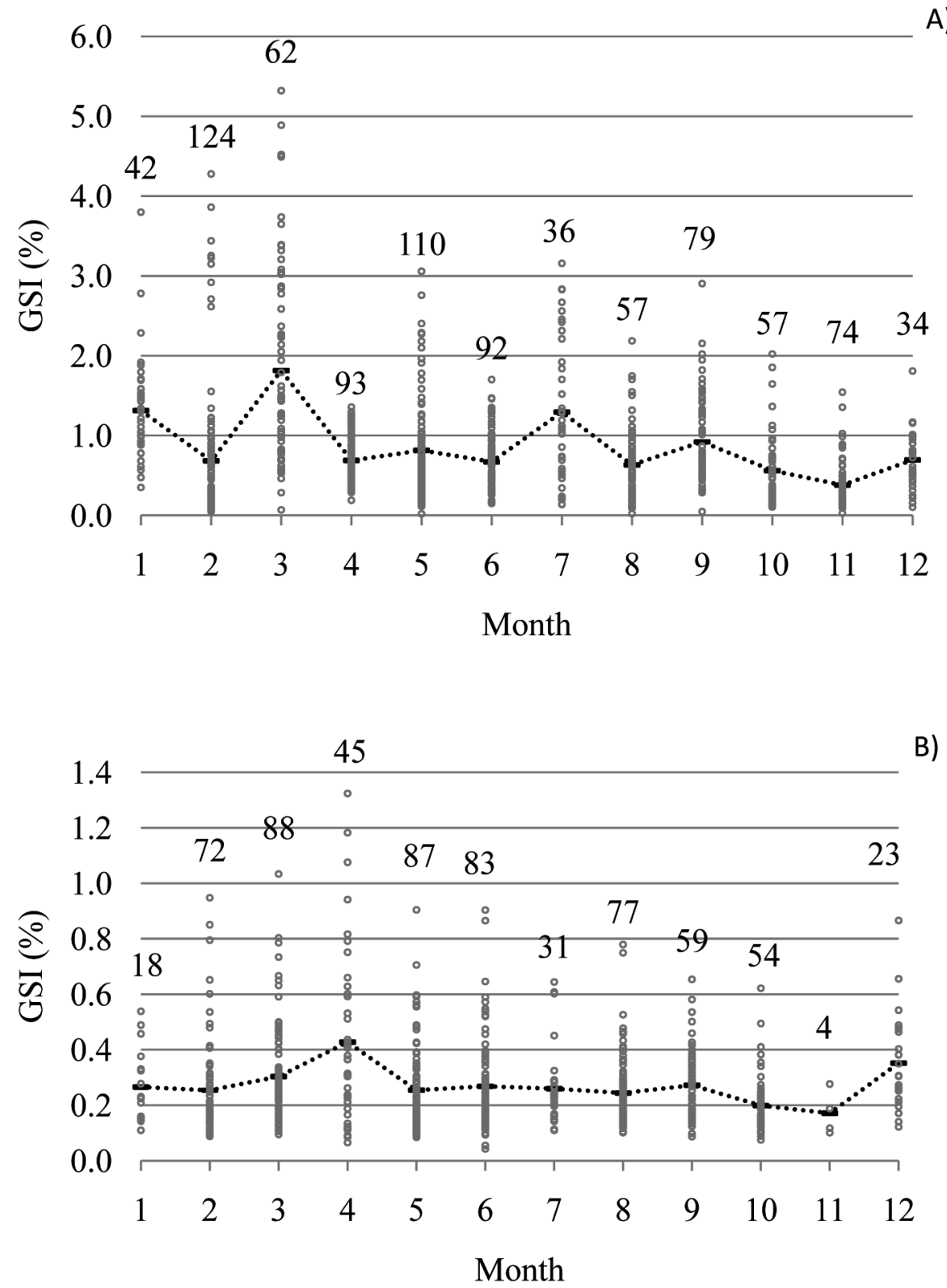

Figure 3. Gonado-Somatic Index (GSI) values for female $(A)$ and male $(B)$ spotcheek emperor from the CNMI pooled monthly from 1998 to 2001. Sample sizes above GSI values.

The CNMI SI spotcheek emperor $\mathrm{L}_{M}$ and $\mathrm{L}_{\mathrm{T}}$ with bias-corrected bootstrap estimated percentile confidence intervals were calculated for the NSI and SSI (Table 2). The $\mathrm{L}_{M}$ from the NSI (21.9 $\mathrm{cm} \mathrm{LF})$ was lower than that for the SSI $(23.2 \mathrm{~cm} \mathrm{LF})$. The $\mathrm{L}_{\mathrm{T}}$ for the spotcheek emperor was $29.0 \mathrm{~cm} \mathrm{LF}$ for the SSI and 29.2 $\mathrm{cm} \mathrm{LF}_{\mathrm{F}}$ for the NSI (Table 3). 
TABLE 3

Estimates of Size at Maturity and Size at Transition, with 95\% Bias-Corrected Bootstrap Confidence Intervals for L. rubrioperculatus from the CNMI

\begin{tabular}{|c|c|c|}
\hline Location $^{a}$ & $\begin{array}{l}\text { Size at Maturity } \\
\qquad(\mathrm{cm})^{b}\end{array}$ & $\begin{array}{c}\text { Size at Transition } \\
(\mathrm{cm})\end{array}$ \\
\hline NSI & $\begin{array}{l}20.5<21.9<22.2 \\
(I, 85 ; M, 420)\end{array}$ & $28.6<29.2<29.4$ \\
\hline SSI & $\begin{array}{l}22.6<23.2<23.5 \\
(\mathrm{I}, 141 ; \mathrm{M}, 280)\end{array}$ & $28.2<29.0<29.8$ \\
\hline
\end{tabular}

${ }^{a}$ SSI: Tinian, Saipan, and Marpi Reef; NSI: FDM and Sonome Reef.

${ }^{b} \mathrm{I}$, number sexually immature; $\mathrm{M}$, number sexually mature.

Alsop and West (2003) utilized a dimensionless theory approach (Charnov and Skuladottir 2000) to determine the size and/or age that a hermaphroditic fish could be expected to change sex. It was found that fishes change sex when they are about $80 \%$ of their maximum body size. Given that the $\mathrm{L}_{\mathrm{T}}$ for the spotcheek emperor was found to be about $29.1 \mathrm{~cm} \mathrm{~L}$, using the model of Alsop and West (2003) would yield a maximum length of about $36.3 \mathrm{~cm} \mathrm{LF}$. When viewed in context as an estimate of $\mathrm{L}_{\infty}$ for CNMI spotcheek emperors, this value is about $5 \mathrm{~cm}$ above the lowest $\mathrm{L}_{\infty}$ calculated from age-based methods and about $2 \mathrm{~cm}$ above the length-based result (Table 4). The utility of the Alsop and West (2003) model should be further explored as a useful method to additionally estimate $\mathrm{L}_{\infty}$ in life history studies of hermaphroditic fish species.

Plots of the relative positions of $\mathrm{L}_{M}$ and $\mathrm{L}_{\mathrm{T}}$ on length-frequency histograms for the NSI and SSI indicated that the majority of the NSI landings were well above the two reproductive milestones, but for the SSI the position of $\mathrm{L}_{\mathrm{T}}$ on the SSI histogram was less conclusive, especially given the small SSI sample size (Figure 4).

\section{Age and Growth}

A transverse-sectioned otolith depicting annual increments is shown in Figure 5. The maximum age estimated for spotcheek emperor in this study was for a year-8 fish from NSI, but five year-7 fish were recorded, one from the SSI and four from the NSI. Otolith readings indicated that the growth rate of the spotcheek emperor is very high initially be-

TABLE 4

Estimates of the Parameters $\mathrm{L}_{\infty}$ and $k$ for L. rubrioperculatus from Age- and Length-Based Models

\begin{tabular}{|c|c|c|c|c|}
\hline Parameters $^{a}$ & $\mathrm{~L}_{\infty}$ & $k$ & $t_{0}$ & Data Source \\
\hline \multicolumn{5}{|l|}{ CNMI } \\
\hline \multicolumn{5}{|l|}{ Age-based } \\
\hline Combined $(286)$ & 31.5 & 0.80 & -0.52 & CNMI DFW \\
\hline Males $_{(89)}$ & 31.5 & 0.82 & -0.85 & CNMI DFW \\
\hline Females $_{(193)}$ & 29.8 & 0.88 & -0.38 & CNMI DFW \\
\hline $\mathrm{NSI}_{(161)}$ & 30.8 & 1.39 & 0.15 & CNMI DFW \\
\hline $\mathrm{SSI}_{(125)}$ & 33.2 & 0.67 & -0.87 & CNMI DFW \\
\hline \multicolumn{5}{|l|}{ Length-based } \\
\hline Combined $_{(10,343)}$ & 35.2 & 0.67 & -0.87 & CNMI DFW \\
\hline \multicolumn{5}{|l|}{ Other locations } \\
\hline \multicolumn{5}{|l|}{ Age-based } \\
\hline Ryukyu Islands $(652)$ & 38.3 & 0.42 & -0.80 & Ebisawa and Ozawa (2009) \\
\hline American Samoa $_{(75)}$ & 30.8 & 0.22 & -0.40 & Ralston and Williams (1988) \\
\hline New Caledonia $(529)$ & 33.9 & 0.43 & -0.38 & Loubens $(1980)^{b}$ \\
\hline \multicolumn{5}{|l|}{ Length-based } \\
\hline Mauritius $_{(1,012)}$ & 57.1 & 0.18 & & Hanoomanjee and Soondron (1999) \\
\hline
\end{tabular}

\footnotetext{
a Sample size in parentheses. SSI: Tinian, Saipan, and Marpi Reef; NSI: FDM and Sonome Reef.
}

${ }^{b}$ Loubens (1980) listed species as L. variegatus. 

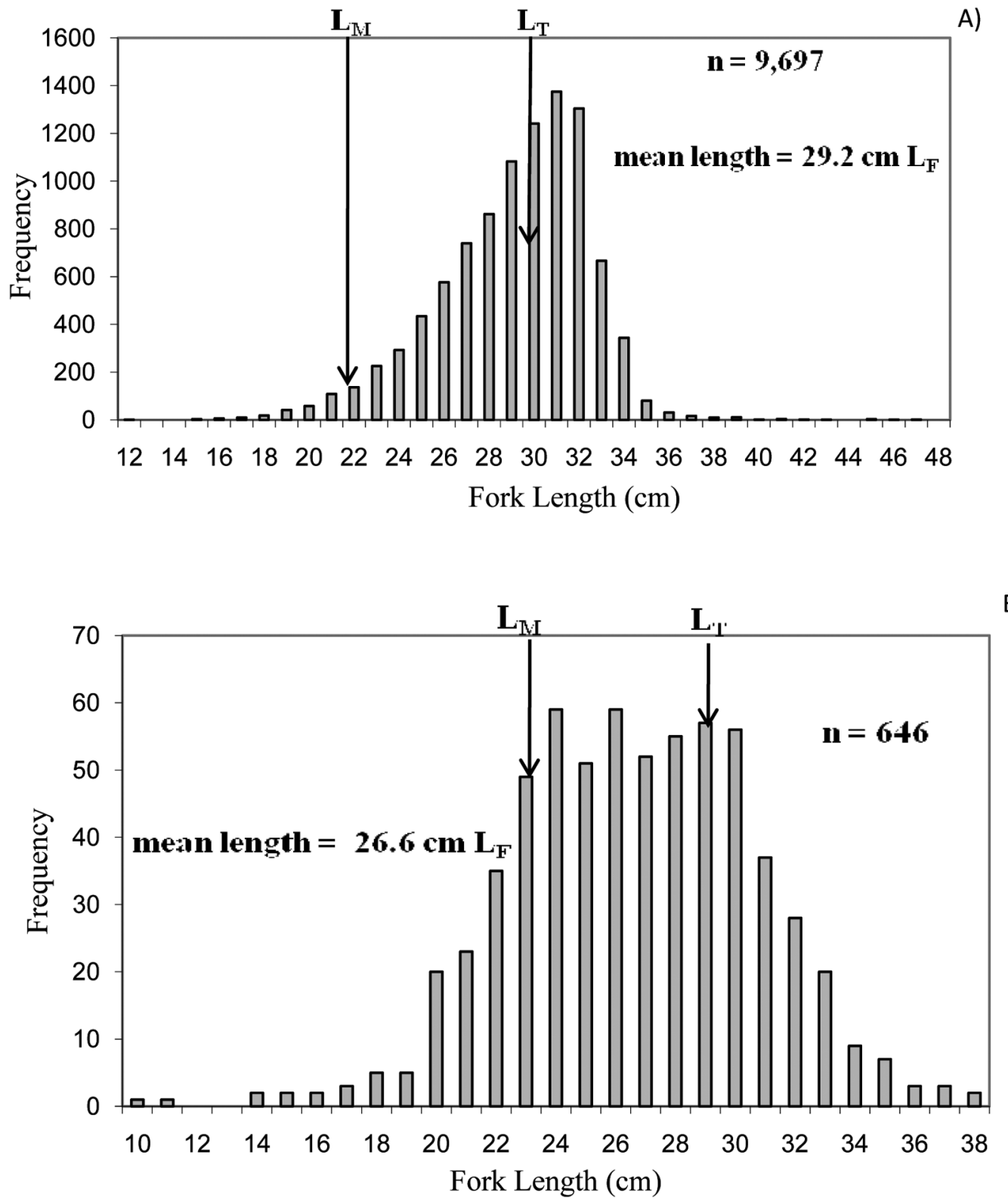

B)

FIgURE 4. Plots of the approximate positions of $\mathrm{L}_{\mathrm{M}}$ and $\mathrm{L}_{\mathrm{T}}$ on length-frequency histograms for the NSI $(A)$ and SSI (B).

cause year-0 individuals averaged $21.0 \mathrm{~cm} \mathrm{~L}$, with growth subsequently decreasing because year-7 individuals varied in size from 28 to $34 \mathrm{~cm} \mathrm{LF}$ (Figure 6). A total of 30 spotcheek emperors was classified as year 0 from annual increment age estimation. In addition, five specimens were recorded as year 0 during one of the three blind annual increment age estimation otolith reads. Of the 300 -age otoliths, 15 were less than 365 days old, and the other 


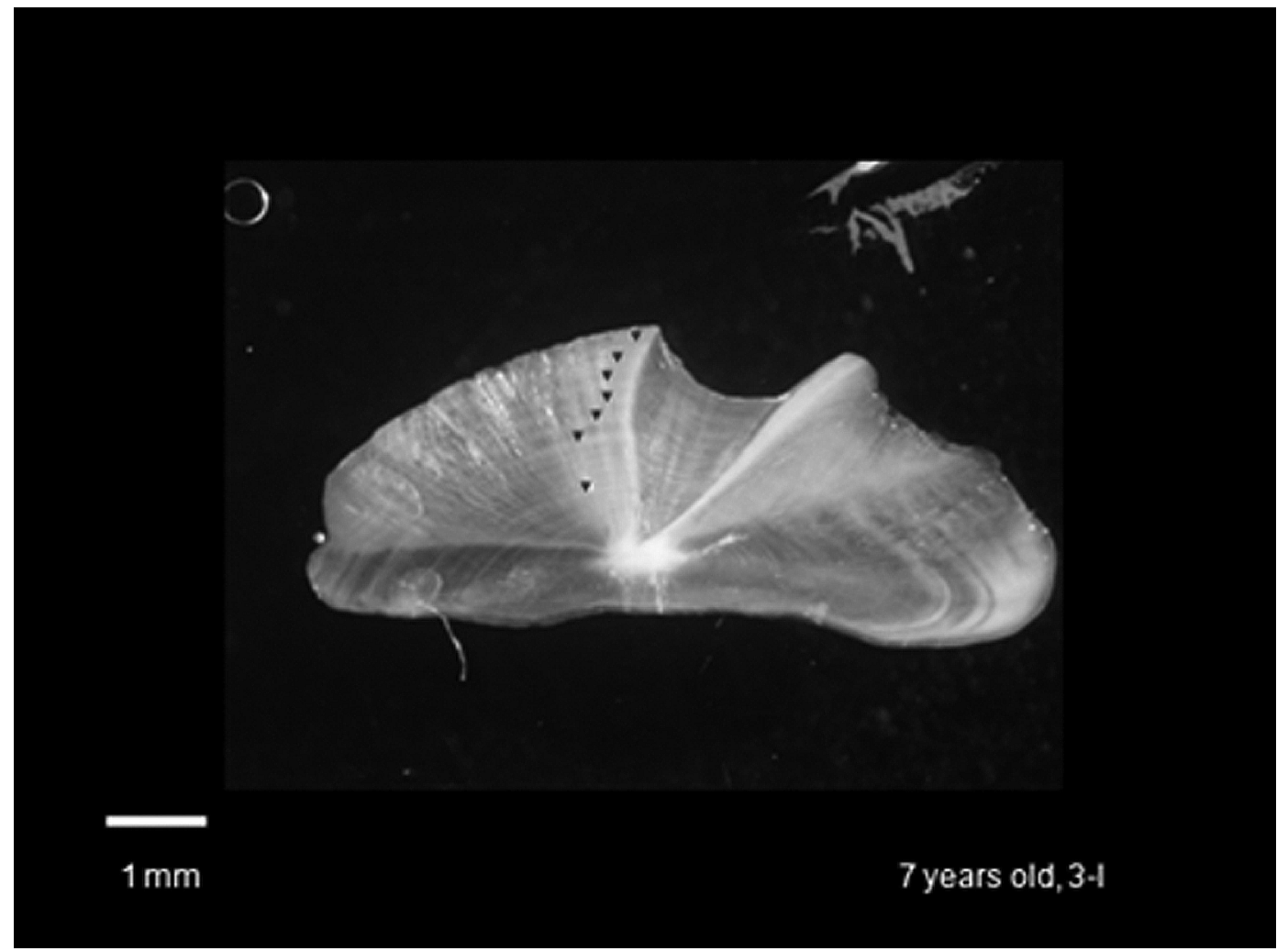

FIgURE 5. Transverse section of processed and aged otolith of a year-7 spotcheek emperor specimen from the CNMI SI.

15 ranged from 1.03 to $1.30 \mathrm{yr}$ old as determined from the counting of daily rings. Three otoliths read as year 1 from annual increment age estimation were less than 365 days old. The average length of year-0 spotcheek emperor from the SSI was $22.2 \mathrm{~cm} \mathrm{LF}$, compared with $18.7 \mathrm{~cm} \mathrm{LF}$ from the NSI. All year-0 fish were female, with year-0 FDM fish smallest in size (Figure 7). Linear and second-order polynomial models fit to weight on age resulted in positive correlations (linear $r^{2}=0.75$; polynomial $\left.r^{2}=0.77\right)$, indicating that otolith weight has potential as a useful proxy to determine age of spotcheek emperor in the Southern Islands of the CNMI (Figure 8). A frequency plot of sex on otolith weight showed that low otolith weights were mostly of females, and heavier otolith weights were associated with males (Figure 9).
Estimates of $k$ and $\mathrm{L}_{\infty}$ from age- and lengthbased fitted VB growth curves are listed in Table 4. Age-based estimates from the CNMI for females and males were similar, although estimates from the NSI and SSI differed markedly with respect to $k$. Estimates of $k$ from the NSI were nearly three times the value of $k$ estimated from the SSI. The analysis of residual sum of squares method (ARSS) for the age-based growth curves from the NSI and SSI was significant at the $5 \%$ level $(P=.018)$, but no significance was found between female and male growth curves. Coupled quarterly data used in the length-based estimate of $k$ and $\mathrm{L}_{\infty}$ generated by ELEFAN are shown in Figure 10. Length-based estimates resulted in a slightly lower $k$ value than the "Combined" age-based estimate and slightly larger $\mathrm{L}_{\infty}$ estimate (Table 4). 


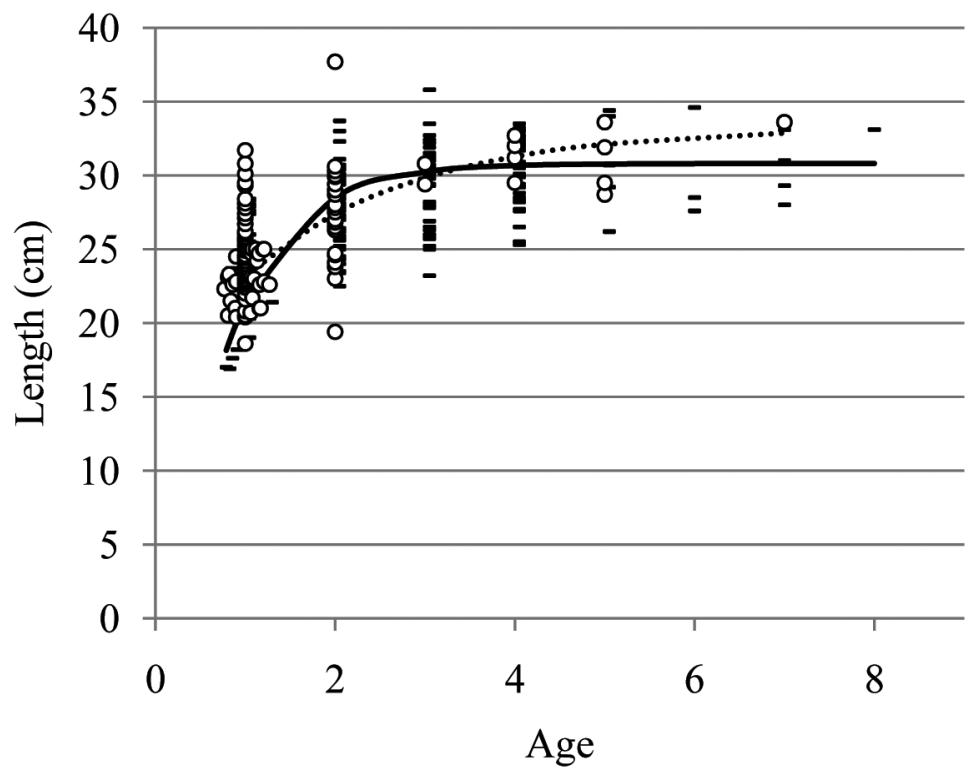

A)

- NSI

○ SSI

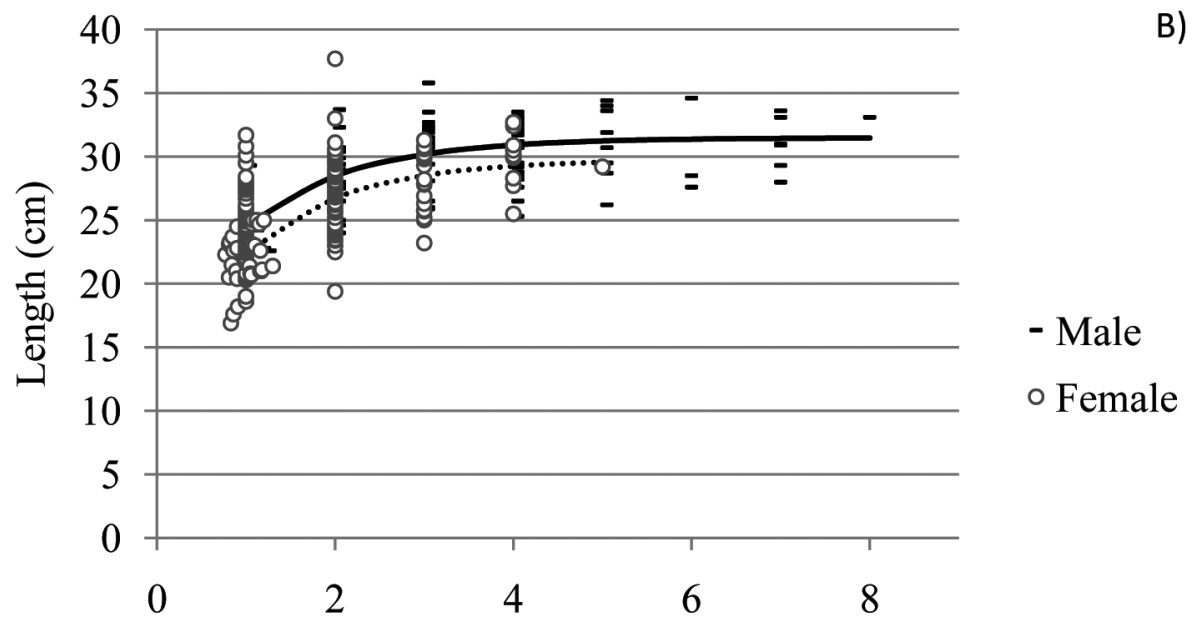

Age

Figure 6. The von Bertalanffy growth equation fitted to spotcheek emperor length-age data from the CNMI for NSI versus SSI $(A)$ and female versus male $(B)$.

The correlation of weight on length for spotcheek emperor resulted in a good fit $\left(W=0.02353 \times \mathrm{L}^{2.92}, r^{2}=0.968, n=1,834\right)$. Length-weight relationships determined for five sites (Sonome, FDM, Marpi, Saipan, and Tinian) all resulted in strong correlations
(Table 5). Length-weight slopes for Saipan, FDM, and Sonome Reef were found to be significantly smaller than 3 , indicating a negative allometric condition, but slopes from the other two sites were not found to be significantly different from 3 (Table 5). 


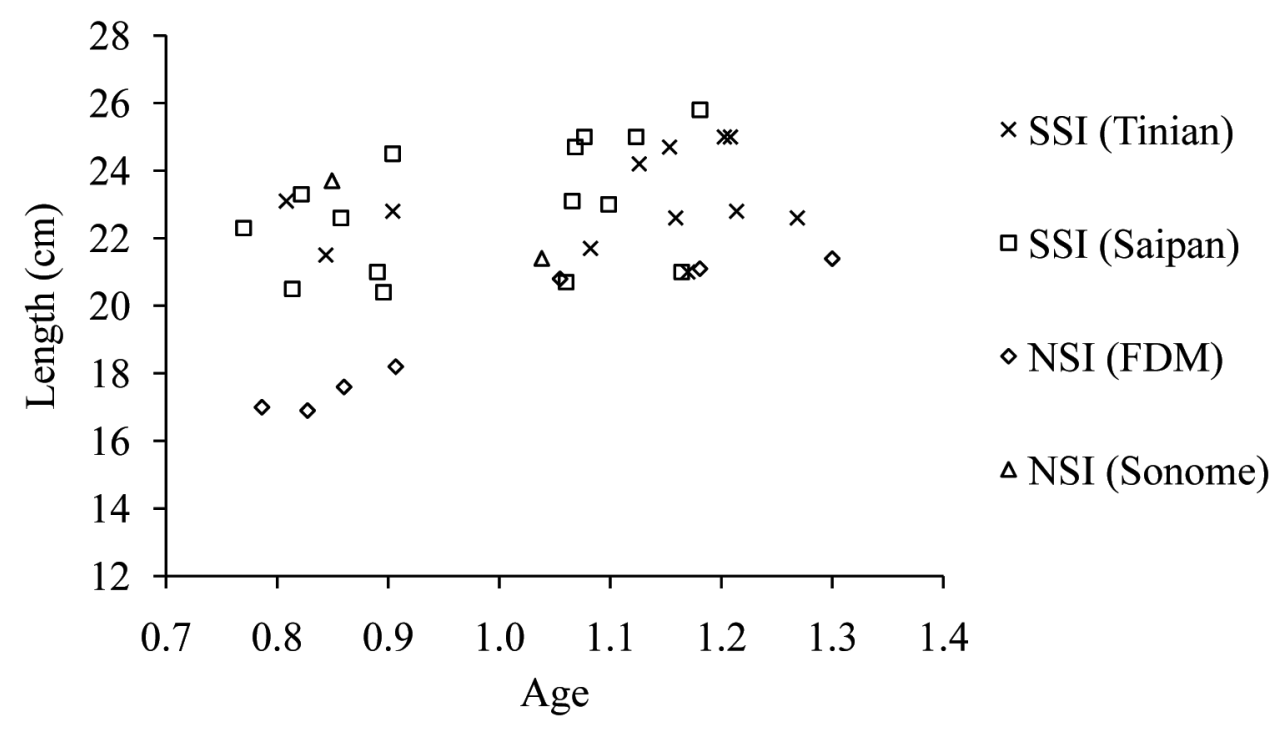

FIGURE 7. Plot of length over age for year-0 fish examined by daily ring counts.

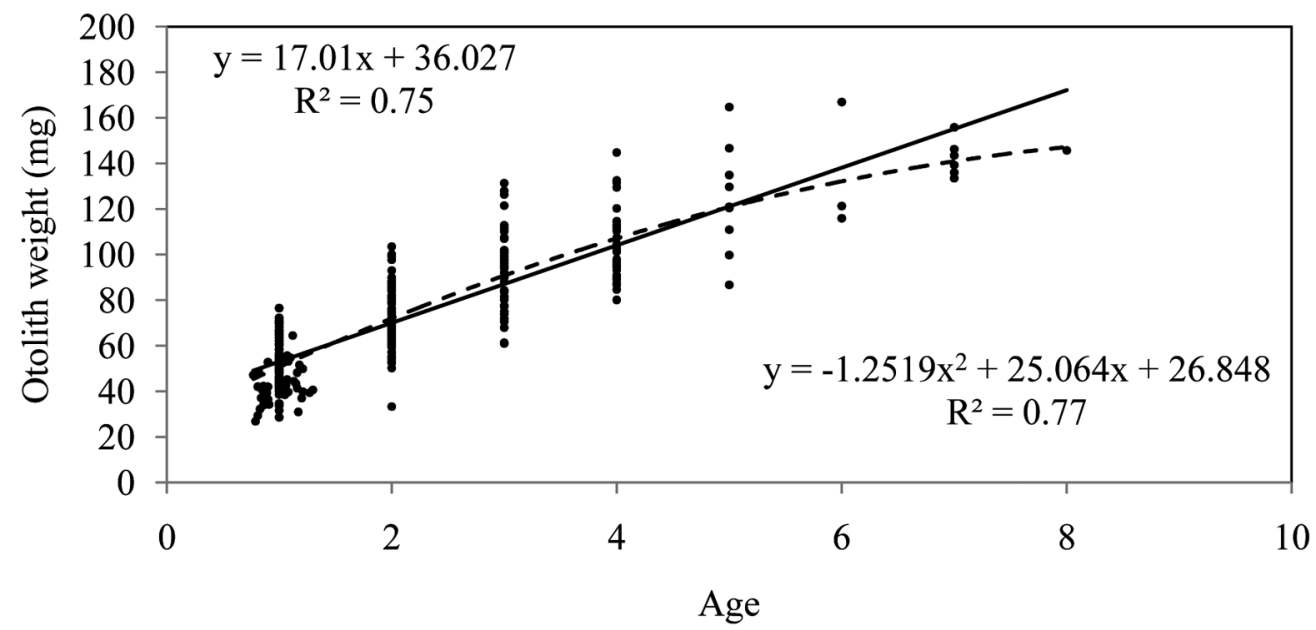

FIGURE 8. Linear and second-order polynomial regressions of otolith weight on age for the spotcheek emperor from the southern islands of the CNMI.

\section{DISCUSSION}

The sex ratios obtained from this study appear to indicate that male spotcheek emperors are depleted in the SSI, especially around Saipan and Tinian. Although sex ratios were divergent in fished areas in the Ryukyu Islands, in particular Okinawa, the results from
Saipan and Tinian compared with other locations were distinctive, considering that CNMI DFW research survey data-collection methodology was standardized. Most of the literature pertaining to fishing-induced sex ratio changes indicates that reproductive characteristics, such as grouper spawning aggregations, might make certain sexes more vulner- 


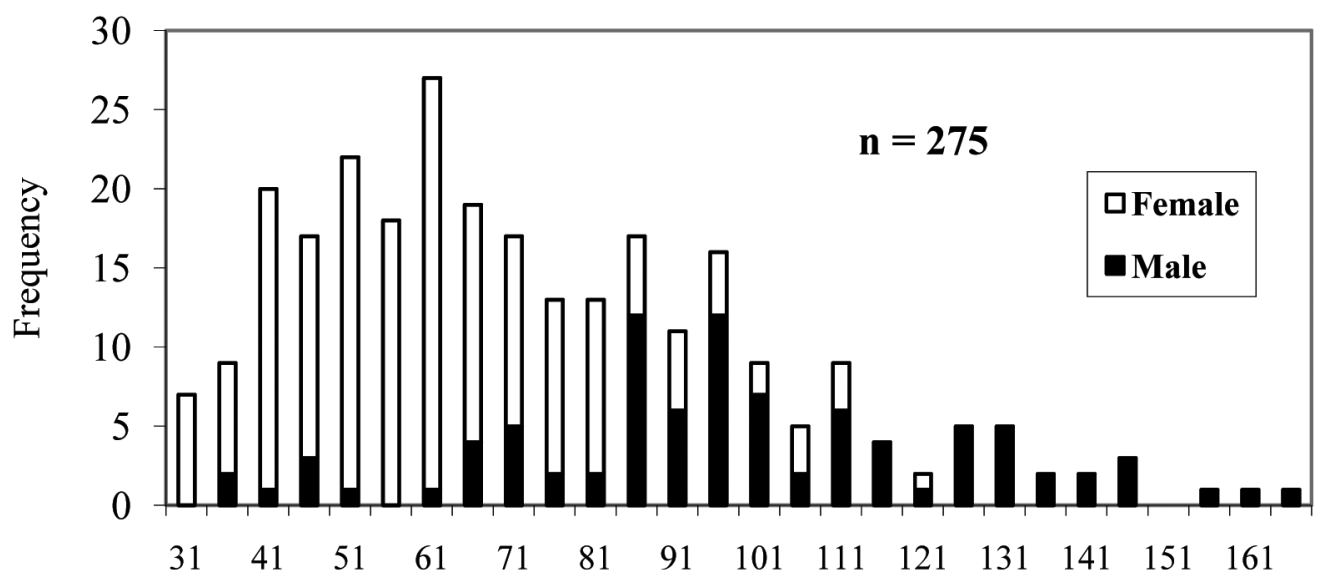

Otolith Weight (mg)

FIGURE 9. Frequency histogram of otolith weight by sex for spotcheek emperor from the southern islands of the CNMI.

able to fishing gear (McGovern et al. 1998, Beets and Friedlander 1999). DeVries (2007), however, found that hook and line fishing may not necessarily result in size or sex selectivity in protogynous species. The spotcheek emperor is a shoaling species, and perhaps a pair spawner (Ebisawa 1997), characteristics that would imply a low fishing selectivity. The lack of a significant difference in sex ratios between commercial and research survey data from FDM suggests that differences observed between the SSI and NSI were not due to differences in selectivity as a result of commercial versus research fishing methods. Future evaluation of sex ratios for the spotcheek emperor in the CNMI should include the use of various hook sizes at all locations identified in this study.

The results for $\mathrm{L}_{M}$ obtained in this study fell within the range reported by Ebisawa (1997), who used histological evaluation to estimate that $\mathrm{L}_{\mathrm{M}}$ began at about $20 \mathrm{~cm} \mathrm{~L} \mathrm{~L}_{\mathrm{F}}$ and was complete by $26 \mathrm{~cm} \mathrm{LF}$ for spotcheek emperor in the Ryukyu Islands. Although Ebisawa (1997) did not estimate $\mathrm{L}_{\mathrm{T}}$, it was noted that only $0.01 \%$ of the fish evaluated from the Ryukyu Islands exhibited sexually transitional gonads. Ebisawa and Ozawa (2009) estimated the age at which sex ratio reached $50 \%$, as indicative of age at transition, to be about $4 \mathrm{yr}$ in Okinawa and reported 5-6 yr for the same metric from New Caledonia after Loubens (1980). The $\mathrm{L}_{\mathrm{T}}$ estimates from the study reported here correspond to about $3-4 \mathrm{yr}$ of age. The estimation of $\mathrm{L}_{\mathrm{M}}$ and $\mathrm{L}_{\mathrm{T}}$ will prove useful as a landmark for future spotcheek life history studies involving histological work, as well as for the evaluation of fishing pressure on spatially distinct populations, particularly with respect to $\mathrm{L}_{\mathrm{T}}$ because histological evaluation of that life history milestone is recognized as being critical in the management of hermaphroditic species (Alonzo and Mangel 2004).

Ebisawa (1997) concluded that the spotcheek emperor exhibited a postmaturational protogynous hermaphroditic sexual transition mode, because the smallest male sampled was larger than $\mathrm{L}_{\mathrm{M}}$ from both Okinawa and Yaeyama samples. The CNMI spotcheek emperor population samples followed a similar pattern, and validation should be confirmed via histological examination.

The spawning seasons in the CNMI and Ryukyu Islands of Japan overlapped, with the peak period in the CNMI during winter/ spring, in contrast to the summer in the Ryukyu Islands (Ebisawa 1997). A correlation 

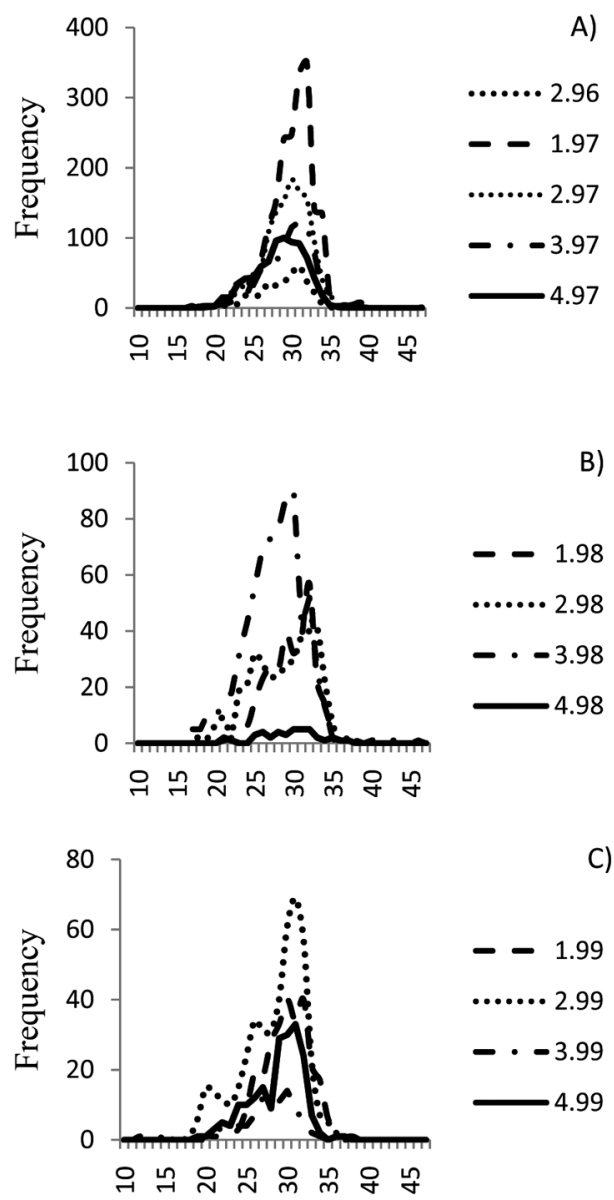

C)

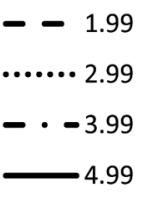

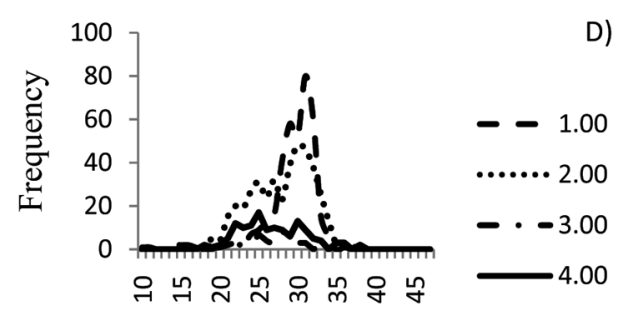

Fork Length $(\mathrm{cm})$

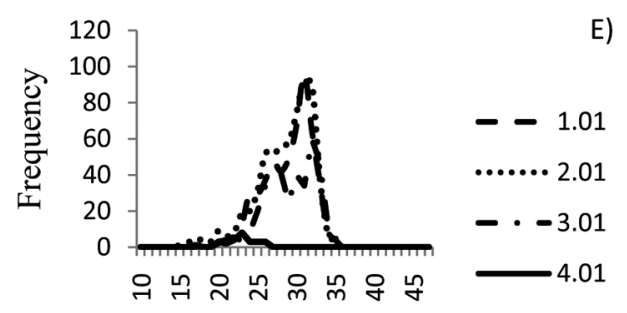

Fork Length $(\mathrm{cm})$

FIGURE 10. Quarterly pooled length-frequency data by year used in estimation of length-based von Bertalanffy parameters: $A, 1997 ; B, 1998 ; C, 1999 ; D, 2000 ; E, 2001$ (e.g., "1.98" = first quarter, 1998).

TABLE 5

Length-Weight Parameters for L. rubrioperculatus from Five Locations in the Southern Islands of the CNMI

\begin{tabular}{lccccccc}
\hline \hline Site & $n$ & Formula & $r^{2}$ & $b$ & SE & $95 \%$ CI & $t$ Value \\
\hline FDM & 814 & $\mathrm{~L}=0.024 \times W^{2.909}$ & 0.96 & 2.909 & 0.020 & $2.870-2.949$ & $-4.465^{*}$ \\
Sonome & 401 & $\mathrm{~L}=0.027 \times W^{2.877}$ & 0.96 & 2.877 & 0.030 & $2.817-2.936$ & $-4.073^{*}$ \\
Marpi & 208 & $\mathrm{~L}=0.017 \times W^{3.020}$ & 0.96 & 3.020 & 0.043 & $2.936-3.104$ & 0.474 \\
Saipan & 174 & $\mathrm{~L}=0.023 \times W^{2.922}$ & 0.98 & 2.922 & 0.028 & $2.867-2.977$ & $-2.786^{*}$ \\
Tinian & 128 & $\mathrm{~L}=0.018 \times W^{3.012}$ & 0.98 & 3.012 & 0.040 & $2.933-3.090$ & 0.293
\end{tabular}

Note: $n$, sample size; $b$, slope; SE, standard error; CI, confidence interval.

${ }^{*}$ Indicates significance at $.05 \%$ level. 
of increasing water temperature and spawning activity was observed by Ebisawa (1997) in the Ryukyu Islands, where annual water temperature ranges about $11^{\circ} \mathrm{C}$ annually. Water temperature was not recorded in the study reported here, although the annual range in the CNMI is about $2.5^{\circ} \mathrm{C}$ and is probably not an influential factor in spawning activity. The winter/spring peak spawning season in the CNMI SI corresponds with the "trade winds" season, which may serve to enhance larval transport and nutrient enrichment provided by localized currents and upwelling. Sustained swimming abilities of late pelagic stage coral reef fishes, including species of the family Lethrinidae, have been shown to be sufficient to modify dispersal (Leis and Carson-Ewart 1997, Stobuzki and Bellwood 1997) and even substantially influence dispersal patterns relative to oceanic processes such as average ocean currents, facilitating active self-recruitment (Fisher 2005). How oceanic processes and larval swimming abilities influence selfrecruitment and dispersal patterns for spotcheek emperor will be useful in understanding stock structure for this species in the CNMI.

The VB parameters calculated from agebased approaches for $k$ and $\mathrm{L}_{\infty}$ indicated faster growth of the species in the CNMI compared with results from other jurisdictions (Table 4). These differences were most relevant to the younger age classes in the CNMI. The length-age data from the CNMI contrasted markedly with length-age data for the spotcheek emperor derived by Ralston and Williams (1988), who used a numerical integration technique to estimate daily growth rings. The length-age plot from the CNMI indicated rapid growth within the first year. The average size of year- 1 age fish was 24.5 $\mathrm{cm} \mathrm{L}_{\mathrm{F}}$ from the CNMI and about $10.5 \mathrm{~cm} \mathrm{~L}$ from American Samoa (Ralston and Williams 1988). Loubens (1980) estimated growth by direct interpretation of annual markings and reported an average length of $13.8 \mathrm{~cm} \mathrm{~L}$ for a year-1 fish from New Caledonia, and year-1 fish from the Ryukyus were about $19 \mathrm{~cm} \mathrm{LF}$ (Ebisawa and Ozawa 2009). The significant difference in growth curves between the SSI and NSI requires further elucidation, because this result could be an artifact of sampling, differing ecosystem characteristics, or disparate stocks.

Comparatively, the oldest fish from the CNMI was a $33.1 \mathrm{~cm} \mathrm{~L} \mathrm{~L}_{\mathrm{F}}$ year-8 male, the oldest fish reported by Loubens (1980) was a year-15 male, by Ebisawa and Ozawa (2009) a year-13 female, and from the Great Barrier Reef a sex-unidentified year-11 fish (D. C. Lou, pers. comm.). Comparing maximum ages for a species from differing jurisdictions poses a number of challenges. Considerable variation among jurisdictions would be expected to occur with regard to commercial fishing effort and fishing power, as well as research survey harvest methods including fishing line strength, hook size, hook type, and retrieval system, all of which would play an important role in size selection. This is apparent from the age-length data for spotcheek emperor presented by Ebisawa and Ozawa (2009), where fish younger than year 1 were not observed in commercial catches, and, conversely, where larger and older fish were documented in contrast to the research survey and commercial samples from the study reported here. In addition, latitudinal and mean annual water temperature differences may also play a factor. The Ryukyu Islands are subtropical at about $26^{\circ} \mathrm{N}$, with a water temperature range of $19-30^{\circ} \mathrm{C}$; New Caledonia about $22^{\circ} \mathrm{S}$, with a water temperature range of $20-23^{\circ} \mathrm{C}$; the Great Barrier Reef year- 11 fish was from about $20^{\circ} \mathrm{S}$ (D. C. Lou, pers. comm.), and the water temperature range of the Great Barrier Reef is $22-28^{\circ} \mathrm{C}$. The latitudinal range of age-determined fish in this study was from about $15^{\circ}$ to $16^{\circ} 20^{\prime} \mathrm{N}$, with a water temperature range approximately from $27.5^{\circ}$ to $30^{\circ} \mathrm{C}$. For western Pacific samples of Ctenochaetus striatus, Choat and Robertson (2002) found a positive relationship between maximum age estimates and latitude, and a negative relationship between age and mean annual water temperature. Similar relationships may or may not pertain to other coral reef fish families or coral reef fish species such as the spotcheek emperor, that typically occupy the deeper habitats of the coral reef ecosystem.

Larger specimens were noticeably absent in both the SSI and NSI histograms, although 
$40+\mathrm{cm} \mathrm{LF}$ individuals were observed (Figure 4). The CNMI length-based estimate of $L_{\infty}$ is similar to age-based estimates for the spotcheek emperor from the CNMI and other jurisdictions (Table 4). The age-based estimates of $k$ from the CNMI, in particular the NSI, are much higher than those estimated in other jurisdictions, most likely due to a bias toward younger fish as an artifact of sample size or, as noted by Choat and Robertson (2002) for western Pacific C. striatus, lower latitudinal stocks may exhibit smaller values for $\mathrm{L}_{\infty}$ and consequently larger values of $k$.

Although the application of length-based methods to nonephemeral species has been viewed as ineffectual (Hilborn and Walters 1992), the values of $\mathrm{L}_{\infty}$ and $k$ generated from age- and length-based methods for the CNMI data sets yielded relatively similar results (Table 4). Larger and perhaps more evenly distributed yearly length-frequency sampling may provide improved estimates of lengthbased age and growth parameters for the spotcheek emperor in the CNMI SI, although obtaining consistent levels of sampling in a spatially and temporally variant coral reef fishery such as the CNMI spotcheek emperor fishery will always prove challenging.

Many reef fish species exhibit a "square" growth curve, where numerous age classes accumulate within a few size classes (Choat and Axe 1996, Choat and Robertson 2002). High growth rates during the first years are followed by a leveling off of length in the growth curve as age progresses. Recent studies of subpopulations of Letbrinus miniatus in the Great Barrier Reef exhibit a square growth pattern (Williams et al. 2007), and most of the growth curves displayed for Lethrinus spp. from the Ryukyu Islands also exhibit a square growth pattern (Ebisawa and Ozawa 2009). Craig (1999) pointed out the difficulty and uncertainty in fitting the VB equation to species that exhibit the two distinct patterns of growth that characterize "square" growth curves. Using Acantburus lineatus as an example, Craig (1999) fitted the VB equation to two distinct growth phases, $0-2$ and 3-18 yr, and achieved differing results from both fits, primarily in the estimation of $k$. According to results in the study reported here, nearly $70 \%$ of spotcheek emperor growth can be achieved in the first year, and the VB results are based on the fraction of fish available to the fishery, which includes "older" age-0 fish. The use of otolith weight as a surrogate for otolith readings has received increasing attention over the past several years, with good correlations observed (Pilling et al. 2003, Lou et al. 2005). Otolith weight-length relationships in the study reported here reflect age-length findings that also indicate an early high growth rate for this species (Figure 8). There exists a need to obtain otolith samples from smaller spotcheek emperors to accurately model growth during the first year. Determination of age of year- 0 fish provided a more accurate approximation of spotcheek emperor growth, verifying that this species, at least in the SI of the CNMI, experiences rapid growth in its first year. This observed high growth rate implies resilience to fishing pressure, because most fish landed from the NSI fishery were observed to be above the estimated $\mathrm{L}_{M}$, thereby ensuring a high degree of individual reproductive success. In addition, future sampling of otoliths from fish in more lightly exploited areas will provide better estimates of maximum age, $k$, and $\mathrm{L}_{\infty}$.

\section{CONCLUSIONS}

The commercial harvest history of the spotcheek emperor in the CNMI may very well extend to the Japanese period (19141944). Smith (1947) reported 1941 landings for reef fish resources near the end of the Japanese period, although the majority of data from that period was a limited time series of pelagic landings (Amesbury and HunterAnderson 2003). The extent of the harvest of species such as the spotcheek emperor during the Japanese period is unknown, although without the use of electric or hydraulic retrieval systems and accurate echo-sounding equipment fishing power was lower and therefore historic landings were also probably lower. The fishing activity reported during the Trust Territory of the Pacific Islands (TTPI) period (1948-1977) recently compiled by Amesbury and Hunter-Anderson (2003) indicated nonpelagic fishery harvests, 
although further resolution of landings was not possible.

Amendment 10 to the Fishery Management Plan (FMP) for Bottomfish and Seamount Groundfish of the Western Pacific Region (73 FR 75615) specifically prohibits commercial fishing by vessels equal to or greater than $12.2 \mathrm{~m}$ (40 feet) within $92.6 \mathrm{~km}$ (50 nautical miles) of any island in the CNMI from Rota Island north, including FDM. Commercial vessels that fished the NSI from 1996 to 2008 will be restricted. The 50-100 $\mathrm{m}$ depth zone around FDM composes about $90 \%$ of that depth zone in the SI (excluding Rota). FDM is leased by the U.S. military as a training site. There exists a continual $5.56 \mathrm{~km}$ (3-mile) exclusion zone that is extended to $18.52 \mathrm{~km}$ (10 nautical miles) during military exercises. The $92.6 \mathrm{~km}$ distance from FDM to Saipan provides a spatial access barrier for smaller vessels and for all vessels during rough sea conditions. Hold capacity on smaller vessels is also limited. Assuming a homogenous SI stock, without any large-vessel commercial fishing activity on the "Grand Bank of the Marianas" surrounding the island of FDM, it is unlikely that the spotcheek emperor in the CNMI SI will be considerably impacted by fishing mortality in the near future.

Given the importance of this resource from a cultural and commercial perspective, and that federal annual catch limits and accountability measures requirements will most likely necessitate future stock assessments on this resource, there remains work to be accomplished regarding the variability of life history parameters between locations and appropriate measures for stock delineation. The results of this study illustrate the need to continue to collect and refine data pertinent to this and other target species in the Mariana archipelago.

\section{ACKNOWLEDGMENTS}

I acknowledge both current and former DFW Fisheries Research Section staff who participated in field sampling and specimen processing: the late Jacinto Taman, Anthony Flores, Rudy Pangelinan, Greg Camacho, Ignacio Aldan, Ray Roberto, Kate Moots, and Chris
Alepuyo. Comments from two anonymous reviewers greatly improved the quality of the manuscript.

\section{Literature Cited}

Alonzo, S. H., and M. Mangel. 2004. The effects of size-selective fisheries on the stock dynamics of and sperm limitation in sexchanging fish. Fish. Bull. 102:1-13.

Alsop, D. J., and S. A. West. 2003. Constant relative age and size at sex change for sequentially hermaphroditic fish. J. Evol. Biol. 16:921-929.

Amesbury, J. R., and R. L. Hunter-Anderson. 2003. Review of archaeological and historical data concerning reef fishing in the U.S. flag islands of Micronesia: Guam and the Northern Mariana Islands. Prepared for Western Pacific Regional Fishery Management Council by Micronesian Archaeological Services (http://www.wpcouncil .org/coralreef/Documents/Mariana\% 20Archeological\%20Review\% 20FINAL .pdf).

Beets, J., and A. Friedlander. 1999. Evaluation of a conservation strategy: A spawning aggregation closure for grouper in the Virgin Islands. Environ. Biol. Fishes 5 5:91-98.

Carpenter, K. E., and G. R. Allen. 1989. FAO Species catalogue. Vol. 9. Emperor fishes and large-eye breams of the world (family Lethrinidae): An annotated and illustrated catalogue of lethrinid species known to date. FAO Species Synop. 125 (9).

Charnov, E. L., and U. Skuladottir. 2000. Dimensionless invariants for the optimal size (age) of sex change. Evol. Ecol. Res. 2:1067-1071.

Chen, Y., D. A. Jackson, and H. H. Harvey. 1992. A comparison of von Bertalanffy and polynomial functions in modeling fish growth data. Can. J. Fish. Aquat. Sci. 49:1228-1235.

Choat, J. H., and L. M. Axe. 1996. Growth and longevity in acanthurid fishes: An analysis of otolith increments. Mar. Ecol. Prog. Ser. 134:15-26.

Choat, J. H., and D. R. Robertson. 2002. Age-based studies on coral reef fishes. Pages 57-80 in P. F. Sale, ed. Coral reef 
fishes: Dynamics and diversity in a complex ecosystem. Academic Press, San Diego, California.

Craig, P. C. 1999. The von Bertalanffy growth curve: When a good fit is not enough. Naga 22:28-30.

Dalzell, P. T., T. H. Adams, and N. V. C. Poulin. 1996. Coastal fisheries in the $\mathrm{Pa}-$ cific islands. Oceangr. Mar. Biol. Annu. Rev. 34:395-531.

DeVries, D. A. 2007. No evidence of bias from fish behavior in the selectivity of size and sex of the protogynous red porgy (Pagrus pagrus, Sparidae) by hook-andline-gear. Fish. Bull. 105:582-587.

Ebisawa, A. 1997. Some aspects of reproduction and sexuality in the spotcheek emperor, Lethrinus rubrioperculatus, in waters off the Ryukyu Islands. Ichthyol. Res. 44:201-212.

Ebisawa, A., and T. Ozawa. 2009. Life-history traits of eight Lethrinus species from two local populations in waters off the Ryukyu Islands. Fish. Sci. 75:553-566, doi: 10.1007/s12562-009-0061-9.

Fisher, R. 2005. Swimming speeds of larval coral reef fishes: Impacts on selfrecruitment and dispersal. Mar. Ecol. Prog. Ser. 285:223-232.

Gayanilo, F. C., Jr., and D. Pauly, eds. 1997. The FAO-ICLARM Stock assessment tools (FiSAT) reference manual. FAO Computerized Information Series (Fisheries). No. 8. Rome.

Hanoomanjee, S., and V. Soondron. 1999. An assessment of Letbrinus rubrioperculatus on the Soudan Bank. Pages 151-158 in Proceedings, 3rd Annual Meeting, Agricultural Scientists, Reduit, Mauritius, 17-18 November 1998. Food and Agricultural Research Council.

Hilborn, R., and C. J. Walters. 1992. Quantitative fisheries stock assessment: Choice, dynamics and uncertainty. Chapman and Hall, New York.

Insightful Corp. 2003. S-PLUS 6.2. Insightful Corp., Seattle, Washington (http:// www.insightful.com).

Leis, J. M., and B. M. Carson-Ewart. 1997. In situ swimming speeds of the late pelagic larvae of some Indo-Pacific coral-reef fishes. Mar. Ecol. Prog. Ser. 159:164-174. Lou, D. C., B. D. Mapstone, G. R. Russ, C. R. Davies, and G. A. Begg. 2005. Using otolith weight-age relationships to predict age-based metrics of coral reef fish populations at different spatial scales. Fish. Res. 71:279-294.

Loubens, G. 1980. Biologie de quelques espèces de poissons du lagon NéoCaledonien. III. Croissance. Cah. Indo. Pac. 2:101-153.

McGovern, J. C. D., M. Wyanski, O. Pashuk, C. S. Manooch II, and G. R. Sedberry. 1998. Changes in the sex ratio and size at maturity of gag, Mycteroperca microlepis, from the Atlantic coast of the southeastern United States during 1976-1995. Fish. Bull. 96:797-807.

Nzioka, R. 1979. Observations on the spawning seasons of East African reef fishes. J. Fish Biol. 14:329-342.

Pilling, G. M., E. M. Grandcourt, and G. P. Kirkwood. 2003. The utility of otolith weight as a predictor of age in the emperor Letbrinus mabsena and other tropical fish species. Fish. Res. 60:493-506.

Ralston, S., and H. A. Williams. 1988. Age and growth of Lutjanus kasmira, Letbrinus rubrioperculatus, Acanthurus lineatus and Ctenochaetus striatus in American Samoa. Admin. Rep. 11-18-18, Southwest Fisheries Center: National Marine Fisheries Service (Honolulu Laboratory) (http:// www.botany.hawaii.edu/basch/uhnpscesu/ pdfs/sam/Ralston1988AS.pdf).

Restrepo, V. R., and J. E. Powers. 1999. Precautionary control rules in U.S. fisheries management: Specifications and performance. ICES J. Mar. Sci. 56:846-852.

Secor, D. H., J. M. Dean, and E. H. Laban. 1991. Manual for otolith removal and preparation for microstructural examination. Tech. Publ. 1991-01 of the Belle W. Baruch Institute for Marine Biology and Coastal Research. Published by the Electric Power Institute and the Belle W. Baruch Institute for Marine Biology and Coastal Research, University of South Carolina. 
Smith, R. O. 1947. Survey of the fisheries of Von Bertalanffy, K. L. 1938. A quantitative the former Japanese Mandated Islands. U.S. Fish Wildl. Serv. Fish. Leafl. 273. theory of organic growth. Hum. Biol. 10:181-213.

Stobutzki, I. C., and D. R. Bellwood. 1997. Williams, A. J., B. D. Mapstone, and C. R. Sustained swimming abilities of the late pelagic stages of coral reef fishes. Mar. Ecol. Prog. Ser. 149:35-41. Davies. 2007. Spatial and interannual patterns in growth of an exploited coral-reef fish. J. Fish Biol. 71:970-992, doi: 10.1111/ j.1095-8649.2007.01560.x. 
